\title{
First records of the potyviruses Chilli ringspot virus and Shallot yellow stripe virus from Laos
}

\author{
Khonesavanh Chittarath ${ }^{1}$ - Wasana Rungsawang ${ }^{2}$ - Preyapan Pongsapich ${ }^{2}$. \\ Gary A. Kong ${ }^{3}$ • John E. Thomas ${ }^{4}$ - Andrew D. W. Geering ${ }^{4}$
}

Received: 20 August 2017 / Accepted: 14 September 2017 /Published online: 23 September 2017

(C) Australasian Plant Pathology Society Inc. 2017

\begin{abstract}
Evidence for the presence of Chilli ringspot virus and Shallot yellow stripe virus in Laos is provided for the first time. RT-PCR assays to amplify the coat protein genes of these viruses are described.
\end{abstract}

Keywords Lao People's Democratic Republic · Vegetable disease survey

Laos (Lao People's Democratic Republic) is a land-locked country within South East Asia, and has one of the lowest Gross Domestic Products in the region. There are very few plant virus records of any type from Laos, with only three (Papaya ringspot virus, Tomato leaf curl Laos virus and Tomato leaf curl Kanchanaburi virus) supported by DNA sequence data that have been lodged in the International Nucleotide Sequence Databases (NCBI NR nucleotide database examined on 14 July).

As part of a survey for plant viruses, market gardens in the Mekong River Valley near Vientiane were examined for plants with virus-like disease symptoms on 6-9 July 2015. Leaf samples of two chilli (Capsicum sp.) plants (isolate Q6417,

Andrew D. W. Geering

a.geering@uq.edu.au

1 Plant Protection Center, Department of Agriculture, Ministry of Agriculture and Forestry, P.O. Box 811, Vientiane, Laos

2 Department of Agriculture, Plant Protection Research and Development Office, 50 Paholyotin Rd, Ladyao Chatuchak, Bangkok 10900, Thailand

3 Redclaw Ink Pty Ltd, 110 Finley Rd, Eumundi, Queensland 4562, Australia

4 Queensland Alliance for Agriculture and Food Innovation, The University of Queensland, St Lucia, Queensland 4072, Australia
GPS N17.82267, E102.69134; isolate Q6481, GPS N17.87196, E102.66339), and one shallot (Allium cepa var. aggregatum) plant (isolate Q6489, GPS N18.17402, E102.59745), were collected. The tissue was dried over silica gel and archived in the Queensland Department of Agriculture and Fisheries Plant Virus Collection (Ecosciences Precinct, Dutton Park, Queensland).

Visually positive reactions were observed when the samples were tested using an AGDIA Potyvirus ELISA kit (Cat. SRA 27200) following the manufacturer's instructions. This ELISA test utilizes the PTY 1 monoclonal antibody for detection (Jordan and Hammond 1991) and is a good general screening tool for potyviruses but does not allow virus identification at the species level. More precise diagnoses were made by direct sequencing of the RT-PCR amplicon generated using RNA templates prepared with an ISOLATE II RNA Mini Kit (Bioline), and the potyvirus universal primers U341 and D341 (Langeveld et al. 1991) used with a OneStep RT-PCR Kit (QIAGEN) as per the manufacturer's instructions. Preliminary identifications of the viruses in chilli and shallot were Chilli ringspot virus (ChiRSV) and Shallot yellow stripe virus (ShYSV), respectively. To provide sequence data corresponding to the whole coat protein gene, new PCR primers were designed by downloading all available sequences from the NIb gene and 3 ' untranslated region of each virus species on GenBank, and aligning using the MUSCLE algorithm in the MEGA v.6.06 software package. Conserved sequences were then selected to design the primers ChiRSVNIb (5'TGGTGATAATAACAATGCACTA3') and ChiRSV3UTR (5'TTCCACTACCCAACATTGA3') for the chilli potyvirus, and ShYSVNIb (5'ACGATTTATGGAAG AATG3') and ShYSV3UTR (5'TCAAATATAACGAA AGATAATG3') for the shallot potyvirus. RNA extracts were prepared using an RNeasy Extraction Kit (QIAGEN) and amplifications done with a SuperScript ${ }^{\mathrm{TM}}$ III One-Step RT-PCR 
System (ThermoFisher) as per the manufacturers' instructions. For both primer pairs, the annealing temperature was $48^{\circ} \mathrm{C}$. Amplicons were directly sequenced using the amplification primers.

For both chilli virus isolates Q6417 and Q6481, amplicons of the expected size of $1572 \mathrm{bp}$ were obtained, and when sequenced (sequences deposited as GenBank accessions MF662674 and MF662675, respectively), matched ChiRSV in BLASTN searches of GenBank. Pairwise sequence comparisons were then done using conceptual translations of the coat protein $(\mathrm{CP})$ gene, and both Laotian virus isolates were identical to each other, and had $97.0 \%$ amino acid (aa) identity to the type isolate of ChiRSV from Hainan, China (GenBank accession JN008909.1). The nearest location to the current site where ChiRSV had previously been recorded, is Điện Biên Phủ in northern Vietnam (Ha et al. 2008), which is about $600 \mathrm{~km}$ north-east of Vientiane. This northern Vietnam isolate (DQ925439.1) had only $94.8 \%$ aa identity to the Vientiane isolates, compared to $99.6 \%$ aa identity to an isolate from Hunan Province in central China (KX379001.1). This disjunction between geographic proximity and genetic relatedness of the virus isolates could indicate that human-assisted spread has occurred. Seed transmissibility of ChiRSV has not been studied, but is worthy of future investigation.

For shallot virus isolate Q6489, an amplicon of the expected size of 1559 bp was obtained, and when sequenced (sequence deposited as GenBank accession MF662676), matched ShYSV in a BLASTN search of GenBank. Again, pairwise sequence comparisons were done using the $\mathrm{CP}$, and isolate Q6489 had $97.3 \%$ aa identity to the type isolate of ShYSV (GenBank accession AJ865076.1). All ShYSV isolates were closely related, with a narrow range of sequence variation in the CP (95-99.2\% aa identity), which most likely reflects the fact that shallot is clonally propagated, and spread by trade of infected bulbs is the main mode of dispersal.

Neither plant virus record is entirely unexpected. ChiRSV is present in Vietnam (Ha et al. 2008), and in several provinces in central and southern China, including Sichuan, Hunan and Hainan (Gong et al. 2011; Hu et al. 2015; Wang et al. 2011). ShYSV is likewise present in Vietnam (Ha et al. 2008) and China (Chen et al. 2002), as well as in Thailand (van der Vlugt et al. 1999). ChiRSV has yet to be found in Thailand but further surveillance is warranted, especially in Nong Khai Province, which is immediately across the Mekong River from Vientiane.

Acknowledgements We gratefully acknowledge support from ACIAR Project HORT/2010/069 and the Plant Biosecurity Cooperative Research Centre through the Australian Cooperative Research Centres' Program.

\section{References}

Chen JM, Chen JP, Adams MJ (2002) Characterisation of some carla- and potyviruses from bulb crops in China. Arch Virol 147:419-428

Gong D, Wang J-H, Lin Z-S, Zhang S-Y, Zhang Y-L, Yu N-T, Xiong Z, Liu Z-X (2011) Genomic sequencing and analysis of Chilli ringspot virus, a novel potyvirus. Virus Genes 43:439

Ha C, Revill P, Harding RM, Vu M, Dale JL (2008) Identification and sequence analysis of potyviruses infecting crops in Vietnam. Arch Virol 153:45-60

Hu JY, Liu J, Deng DZ, Yan WX (2015) First report of Chilli ringspot virus infection of Solanum xanthocarpum in China. J Plant Pathol 97:218

Jordan R, Hammond J (1991) Comparison and differentiation of potyvirus isolates and identification of strain-, virus-, subgroupspecific and potyvirus group-common epitopes using monoclonal antibodies. J Gen Virol 72:25-36

Langeveld SA, Dore J-M, Memelink J, Derks AFLM, van der Vlugt CIM, Asjes CJ, Bol JF (1991) Identification of potyviruses using the polymerase chain reaction with degenerate primers. J Gen Virol 72:1531-1541

van der Vlugt RAA, Steffens P, Cuperus C, Barg E, Lesemann DE, Bos L, Vetten HJ (1999) Further evidence that shallot yellow stripe virus (SYSV) is a distinct potyvirus and reidentification of Welsh onion yellow stripe virus as a SYSV strain. Phytopathology 89:148-155

Wang JH, Zhang SY, Gong D, Wu YP, Zhang YL, Yu NT, Liu ZX, Xiong Z (2011) First report of Chilli ringspot virus on chili pepper in China. Plant Dis 96:462 